\title{
Rice seed quality development and temperature during late development and maturation
}

Article

Published Version

Ellis, R. H. (2011) Rice seed quality development and temperature during late development and maturation. Seed Science Research, 21 (2). pp. 95-101. ISSN 0960-2585 doi: https://doi.org/10.1017/S0960258510000425 Available at https://centaur.reading.ac.uk/19921/

It is advisable to refer to the publisher's version if you intend to cite from the work. See Guidance on citing.

Published version at: http://dx.doi.org/10.1017/S0960258510000425

To link to this article DOI: http://dx.doi.org/10.1017/S0960258510000425

Publisher: Cambridge University Press

Publisher statement: (c) Cambridge University Press 2011

All outputs in CentAUR are protected by Intellectual Property Rights law, including copyright law. Copyright and IPR is retained by the creators or other copyright holders. Terms and conditions for use of this material are defined in the End User Agreement.

www.reading.ac.uk/centaur

\section{CentAUR}


Central Archive at the University of Reading

Reading's research outputs online 


\title{
Rice seed quality development and temperature during late development and maturation
}

\author{
Richard H. Ellis* \\ Department of Agriculture, University of Reading, Earley Gate, PO Box 237, Reading RG6 6AR, UK
}

(Received 16 August 2010; accepted after revision 7 November 2010; first published online 13 January 2011)

\begin{abstract}
The potential longevity of japonica rice (Oryza sativa L. subsp. japonica) seed is particularly sensitive to high temperature - and thus climate change - during development and maturation. Cultivar Taipei 309 was grown at $28 / 20^{\circ} \mathrm{C}(12 \mathrm{~h} / 12 \mathrm{~h})$ and then from $19 \mathrm{DAA}$ (days after $50 \%$ anthesis), when seeds were just over half filled, at $28 / 20^{\circ} \mathrm{C}, 30 / 22^{\circ} \mathrm{C}, 32 / 24^{\circ} \mathrm{C}$ or $34 / 26^{\circ} \mathrm{C}$ $(12 \mathrm{~h} / 12 \mathrm{~h})$. Whereas ability to germinate ex planta had been achieved in almost all seeds by 24 DAA, only half the population were desiccation tolerant. Desiccation tolerance continued to increase over the subsequent $28 \mathrm{~d}$, similarly at all four temperatures. Subsequent longevity, assessed by $p_{50}$ (period in days to reduce viability to $50 \%$ in hermetic storage at $40^{\circ} \mathrm{C}$ with c. $15 \%$ moisture content), increased progressively at $28 / 20^{\circ} \mathrm{C}$ until 38 DAA, and remained constant until the final harvest (52 DAA). The three warmer temperature regimes provided similar longevity to $28 / 20^{\circ} \mathrm{C}$ at any one harvest, except at 38 DAA where the warmest $\left(34 / 26^{\circ} \mathrm{C}\right)$ was poorer. That temperature regime also provided greater seed-to-seed variability within each survival curve. The results confirm that appreciable improvement in seed quality occurs during seed development and also subsequent maturation in japonica rice, but that increase in temperature from $28 / 20^{\circ} \mathrm{C}$ to $34 / 26^{\circ} \mathrm{C}$ during late seed filling onwards has comparatively little effect thereon. Comparison with previous investigations suggests that seed quality development may be less sensitive to high temperatures during late development and maturation than during the early seed development that precedes it.
\end{abstract}

Keywords: climate change, desiccation tolerance, germination, Iongevity, Oryza sativa L. subsp. japonica, post-anthesis temperature, seed development

*Correspondence

Email: r.h.ellis@reading.ac.uk

\section{Introduction}

Determining seed survival period ex planta in air-dry, hermetic storage (a sensitive indicator of seed quality) has shown that seed quality continues to improve during seed development and maturation for some considerable time after seed filling ends in cereals (e.g. Pieta Filho and Ellis, 1991; Rao et al., 1991; Ellis and Pieta Filho, 1992), other crops (e.g. Demir and Ellis, 1992a, b, 1993; Sanhewe and Ellis, 1996) and wild species (e.g. Hay and Probert, 1995).

In rice (Oryza sativa L.), similar conclusions have been drawn (Ellis et al., 1993). That study discovered that seed quality development in a japonica rice (cv. Taipei 309) was much more sensitive to high temperature than in javanica and indica rices. Seed filling and the pattern of loss in moisture were almost identical for the japonica rice in the two production regimes investigated (imposed from sowing onwards). However, whereas at $28 / 20^{\circ} \mathrm{C}(12 \mathrm{~h} / 12 \mathrm{~h})$ potential longevity (seed survival period if harvested) continued to increase throughout seed development and maturation until 32 DAA (days after anthesis), in the warmer regime of $32 / 24^{\circ} \mathrm{C}(12 \mathrm{~h} / 12 \mathrm{~h})$ no further improvement occurred beyond 22 DAA (2-3d after seed filling ended), such that seed quality was very much poorer in the warmer regime at the normal time for harvest (Ellis et al., 1993). Moreover, this difference in potential longevity was maintained with no change in either regime for a further $20 \mathrm{~d}$ if harvest was delayed. A parallel investigation showed that the ability to tolerate considerable desiccation to very low moisture contents was similarly poorer in the warmer regime during later stages of seed development and maturation (Ellis and Hong, 1994). Subsequent independent investigations in the field confirmed that japonica seeds produce longer-lived seeds in cooler than warmer regimes (Rao and Jackson, 1996, 1997).

The divergence in japonica rice seed quality development between the two temperature regimes was first detected close to mass maturity (Ellis et al., 1993; Ellis and Hong, 1994), this being the end of the seed-filling phase (Ellis and Pieta Filho, 1992). 
The current study investigated the effect of different temperatures on seed quality development when imposed only from late seed filling onwards. The objective was to determine whether or not, and if so the extent to which, modifying the temperature regime during this late period, rather than throughout development and maturation, affected seed quality.

\section{Materials and methods}

\section{Production of seed material}

Seeds (caryopses enclosed by paleas and lemmas throughout this paper) of the japonica rice cv. Taipei 309, provided by the International Rice Research Institute (IRRI), were graded by eye to remove extremely large or small seeds and sown 4-5 per 18 -cm-diameter pot into a soil-less medium on 8 June 2007. The latter comprised steam-sterilized sand and gravel mixed with peat compost and vermiculite (2:4:1:4 by volume, respectively). The filled pots were soaked with tap water and allowed to drain for $24 \mathrm{~h}$ before sowing and were arranged on four mobile trolleys (each $2.85 \mathrm{~m} \times 0.96 \mathrm{~m}, 15$ rows of 6 pots). The position of each pot on each trolley was recorded. Plants were grown at the Plant Environment Laboratory, University of Reading, UK $\left(51^{\circ} 27^{\prime} \mathrm{N}, 00^{\circ} 56^{\prime} \mathrm{W}\right)$, initially in a controlled-environment, naturally lit, glasshouse with day and light-proof night compartments. The automated mobile trolleys were drawn out from and into night compartments $(3.57 \mathrm{~m} \times 1.74 \mathrm{~m})$ each morning and evening to provide a short, inductive photoperiod of $11 \mathrm{hd}^{-1}$. Temperature (logged continuously at several points) in the greenhouse was maintained at $28 / 20^{\circ} \mathrm{C}$ day/night $(12 \mathrm{~h} / 12 \mathrm{~h})$ through a combination of heating and venting during the day, and heating at night. In general, set temperatures were maintained to within $0.5^{\circ} \mathrm{C}$ (but see below).

The first seedlings emerged 6 DAS (days after sowing) and the majority by 11 DAS. At this time, pots with fewer than three strong seedlings were moved to provide the guard rows on the trolleys, and all pots provided with an automatic drip-feed irrigation system. The number of seedlings was reduced to three per pot at 14 DAS and subsequently thinned to one per pot at the three-leaf stage. The complete nutrient solution contained $100 \mathrm{mgl}^{-1}$ inorganic nitrogen, acidified to $\mathrm{pH} 4.8$ to avoid iron deficiency. Plants were also sprayed with a foliar feed (MiracleGro $^{\circledR}$, The Scotts Company UK Ltd, Godalming, Surrey, UK) at $3.75 \mathrm{gl}^{-1} 68,83$ and 101 DAS and with Torque $\left(50 \% \mathrm{w} / \mathrm{w}\right.$ fenbutatin oxide) at $0.5 \mathrm{gl}^{-1}$ of water to control red spider mites at 61 DAS. Biological control (Phytoseiulus persimilis) of the latter was also applied at 75 and 97 DAS. Aphids detected at 143 DAS were controlled by an application of Savona (an insecticidal soap containing $50 \% \mathrm{w} / \mathrm{w}$ potassium salts of fatty acids).

As panicles reached first anthesis each day they were tagged: $50 \%$ anthesis was reached on 28 September 2007 (112 DAS). Anthesis was protracted across the plant population. To limit this source of variation, only panicles that anthesed 108-114 DAS were used.

The plan had been to move plants to growth cabinets towards the end of the seed-filling phase. However, 2007 was a poor summer and ambient light levels and external temperature in early autumn declined such that plants were moved to four modified Saxil growth cabinets, internal dimensions $1.4 \times 1.4 \times 1.5 \mathrm{~m}$, slightly earlier than planned, on 4 or 5 October [118 or 119 DAS; 6 or 7 DAA, days after $(50 \%)$ anthesis]: plants were staked before moving. All cabinets provided the same regime as the glasshouse $\left(28 / 20^{\circ} \mathrm{C}\right)$, initially.

On 17 October (131 DAS; 19 DAA), each growth cabinet was altered to one of the following regimes: $28 / 20^{\circ} \mathrm{C}, 30 / 22^{\circ} \mathrm{C}, 32 / 24^{\circ} \mathrm{C}, 34 / 26^{\circ} \mathrm{C}(12 \mathrm{~h} / 12 \mathrm{~h})$. On the day before, plants were re-randomized amongst the four cabinets. The carbon dioxide concentration in the cabinets was maintained at $385 \mu \mathrm{mol} \mathrm{mol}^{-1}$ of air. Relative humidity was maintained at $60 \pm 5 \%$ by day and $80 \pm 5 \%$ at night. A combination of cool white fluorescent tubes and incandescent lamps provided a photosynthetic photon flux density (measured at base of cabinet) of $650 \mu \mathrm{mol} \mathrm{m}^{-2} \mathrm{~s}^{-1}$. Irrigation continued until 1 November 2007 (146 DAS; 34 DAA).

Panicles were harvested serially 11 (9 October 2007), 13, 17, 19, 24, 31, 38, 45 and 52 DAA (19 November 2007) throughout seed development and maturation. Each harvest comprised about 30 panicles from 4-8 pots per temperature regime.

Seeds were threshed gently by hand, and empty seeds removed. Samples of 100 seeds plus $1 \mathrm{~g}$ each were withdrawn to determine germination and moisture content, respectively. The remaining seeds were dried in a drying cabinet maintained at $15-17^{\circ} \mathrm{C}$ with $12-15 \%$ relative humidity to $15 \%$ moisture content (one sample for a germination test) or further to $10-14 \%$ moisture content, respectively (wet basis). One subsample was then dried further, over regularly regenerated silica gel at $20^{\circ} \mathrm{C}$, to $4.5 \%$ moisture content and tested for ability to germinate. The remainder was stored hermetically at $3-5^{\circ} \mathrm{C}$ initially, then at $-20^{\circ} \mathrm{C}$ once moisture content was confirmed to be at or below $14 \%$. Seed moisture contents were determined using the high-constanttemperature-oven method (International Seed Testing Association, 2005), except that $2 \times 100$ seed samples were used in place of $2 \times 4-5 \mathrm{~g}$ samples in each case. The two-stage method (International Seed Testing Association, 2005) was used for moist seeds. 


\section{Seed germination and storage}

Samples of seeds (100; two replicates of 50) were tested for germination between moist rolled paper towels in the alternating regime of $34 / 11^{\circ} \mathrm{C}(16 \mathrm{~h} / 8 \mathrm{~h})$ recommended by Ellis et al. (1983) to break dormancy 'safely', for $28 \mathrm{~d}$ initially. Non-germinated seeds that were not soft at this time were then pricked with a needle to promote further loss of dormancy and tests continued until all had germinated (often within a further $7 \mathrm{~d}$, but the most dormant required a much longer duration, sometimes combined with further surgical treatment).

The determination of potential longevity, i.e. seed survival during post-harvest experimental storage, began on 3 March 2008. Seeds were withdrawn from storage at $-20^{\circ} \mathrm{C}$ and held overnight at $20^{\circ} \mathrm{C}$ before opening the packets. Each sample was adjusted to c. $15 \%$ moisture content by humidification above water at $20^{\circ} \mathrm{C}$ for $2-36 \mathrm{~h}$ (depending on initial value) using a target of $75 \%$ equilibrium relative humidity (since this could be assessed repeatedly and non-destructively). The seeds were then stored hermetically at $3-5^{\circ} \mathrm{C}$ for $3 \mathrm{~d}$ for moisture to equilibrate. For each combination of harvest date and temperature regime, 10-14 samples (depending upon number available) of 100 seeds were sealed in separate laminated aluminiumfoil bags. These were stored in an incubator maintained at $40 \pm 0.5^{\circ} \mathrm{C}$ and samples removed for germination tests (as above) at regular intervals for up to $49 \mathrm{~d}$. Mean seed storage moisture content, determined for samples withdrawn from hermetic storage at the end of experimental storage, was $14.6 \%$ (range $14.2-14.9 \%$ ). Seed survival curves were fitted to the data by probit analysis using GENSTAT (Release 10.1, VSN International Ltd, Hemel Hempstead, Herts, UK) in accordance with

$$
v=K_{i}-p / \sigma
$$

where $v$ is viability (normal equivalent deviate) after $p$ days' storage in a constant environment, $K_{\mathrm{i}}$ is the intercept, and $\sigma$ is the standard deviation of the distribution of seed deaths in time (days) (Ellis and Roberts, 1980): the criterion of survival was visible germination.

\section{Results}

The pattern of seed moisture content decline (Fig. 1) was similar to that noted earlier (Ellis et al., 1993), with a tendency for seeds in warmer environments to be slightly drier (from 24 DAA onwards). Seed filling followed the expected linear trend between 11 and 24 DAA $\left(0.83 \mathrm{mg} \mathrm{d}^{-1}\right.$, SE 0.08$)$ and continued until around 30 DAA: the gradient was much reduced beyond 24 DAA, making it difficult to define mass maturity precisely. Mature seed dry weight was $18.9 \mathrm{mg}$ (SE 0.27), with no effect of temperature regime on this value $(P>0.05)$. Hence, treatments in the four different temperature treatments began about twothirds through the period between anthesis and the end of seed filling when seeds were just over half their ultimate dry weight.

Ability to germinate ex planta developed progressively within the population between 11 and 24 DAA (Fig. 2A). Ability to germinate following enforced desiccation to $15 \%$ (Fig. $2 \mathrm{~B}$ ) or $4.5 \%$ moisture content

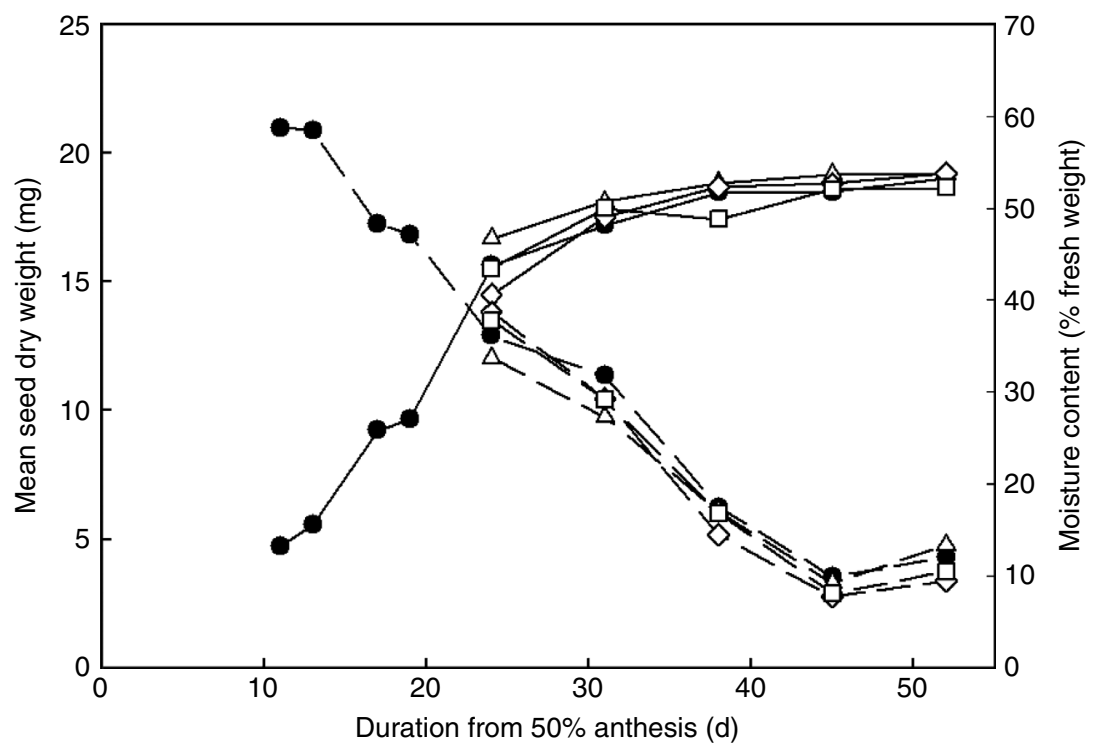

Figure 1. Increase in mean dry weight (solid lines) and decline in moisture content (broken lines) of seeds of japonica rice cv. Taipei 309 harvested serially during their development and maturation from plants grown in controlled environments of $28 / 20^{\circ} \mathrm{C}(\bullet)$ throughout, or at $28 / 20^{\circ} \mathrm{C}$ until $19 \mathrm{DAA}$ and then $30 / 22^{\circ} \mathrm{C}(\triangle), 32 / 24^{\circ} \mathrm{C}(\diamond)$ or $34 / 26^{\circ} \mathrm{C}(\square)$ thereafter. 


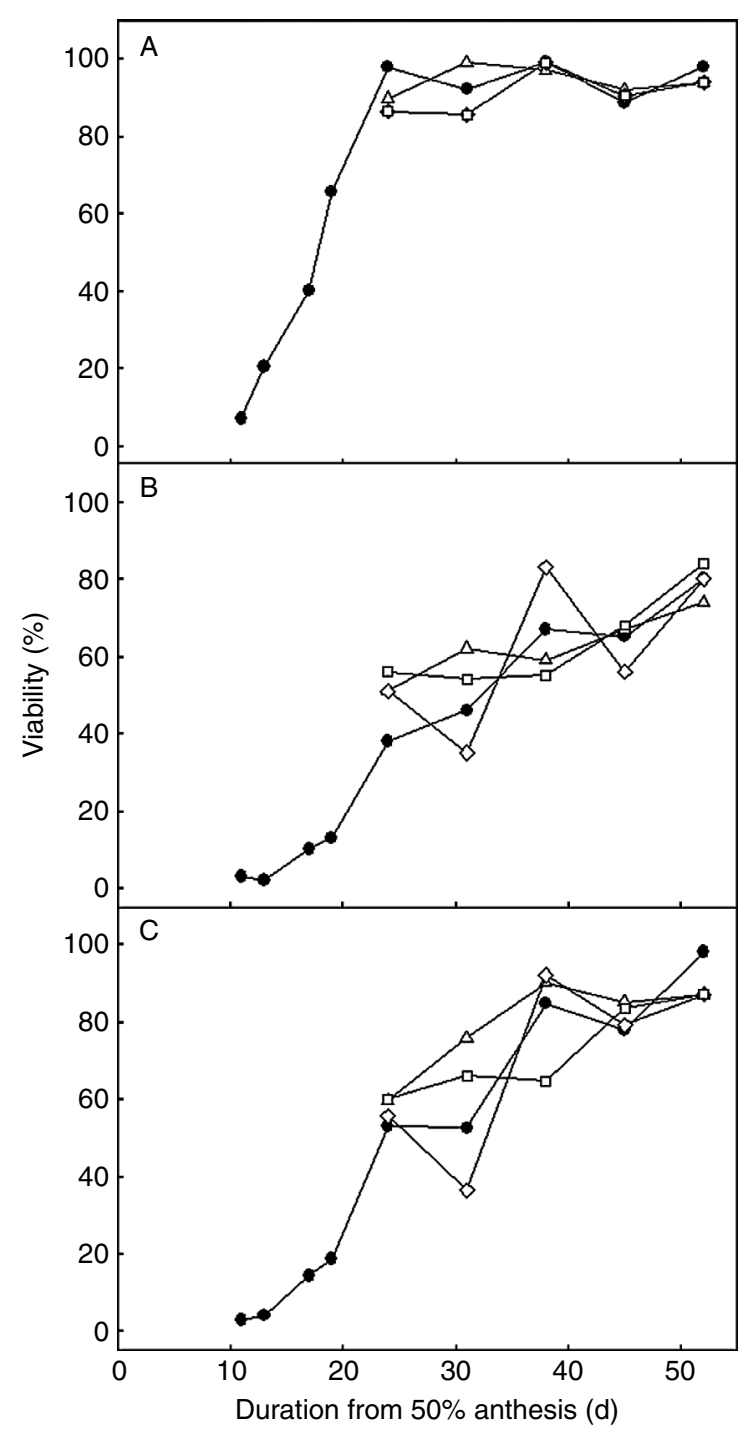

Figure 2. Changes in viability (ability to geminate ex planta in standard tests at $34 / 11^{\circ} \mathrm{C}$ ) for seeds of japonica rice cv. Taipei 309 freshly-harvested (A), or dried to $15 \%$ moisture content (B) or to $4.5 \%$ moisture content $(\mathrm{C})$, when harvested serially during their development and maturation, from plants grown in controlled environments of $28 / 20^{\circ} \mathrm{C}(\boldsymbol{)})$ throughout, or at $28 / 20^{\circ} \mathrm{C}$ until $19 \mathrm{DAA}$ and then $30 / 22^{\circ} \mathrm{C}(\triangle)$, $32 / 24^{\circ} \mathrm{C}(\diamond)$ or $34 / 26^{\circ} \mathrm{C}(\square)$ thereafter. Seed filling ended close to 30 DAA (Fig. 1).

(Fig. 2C) developed less rapidly, but nevertheless progressively and consistently throughout the population(s) from 13 to 52 DAA. The three different warmer temperature regimes, imposed when most seeds were able to germinate ex planta but only about one-fifth were desiccation tolerant (Fig. 2), provided somewhat more variable results than $28 / 20^{\circ} \mathrm{C}$, but there was no evidence of any consistent effect of temperature on the trend of improving desiccation tolerance throughout seed maturation. Similarly, there was no evidence that further desiccation from 15\% (Fig. 2B) to $4.5 \%$ moisture content (Fig. $2 \mathrm{C}$ ) reduced viability.
Negative sigmoidal seed survival curves were obtained in hermetic air-dry storage for each harvest in the four different temperature regimes, as the examples for 38 and 52 DAA (Fig. 3) show. The lower initial viability of dry seeds prepared for experimental storage in early harvests (as in Fig. 2B) resulted in shorter survival periods - whereby longevity increased during seed development and maturation (Fig. 4). In the final harvest (52 DAA), almost all seeds were viable and desiccation tolerant before experimental storage began (Fig. 3B).

Each harvest provided seed survival curve shapes compatible with those of Ellis et al. (1993). Whereas the mode of the distribution of seed deaths in time (i.e. the pattern of loss in viability from around 80 to $20 \%$ with storage period) was broadly similar amongst the three cooler temperatures, Fig. 3 shows that the warmest regime $\left(34 / 26^{\circ} \mathrm{C}\right)$ tended to show a shallower curve (i.e. more variation in individual seed lifespans within the population) until around $20-40 \%$ viability, with the remainder of the curve (i.e. the longest-lived seeds within the population) differing less from the cooler temperatures. Accordingly, the seed survival curves,

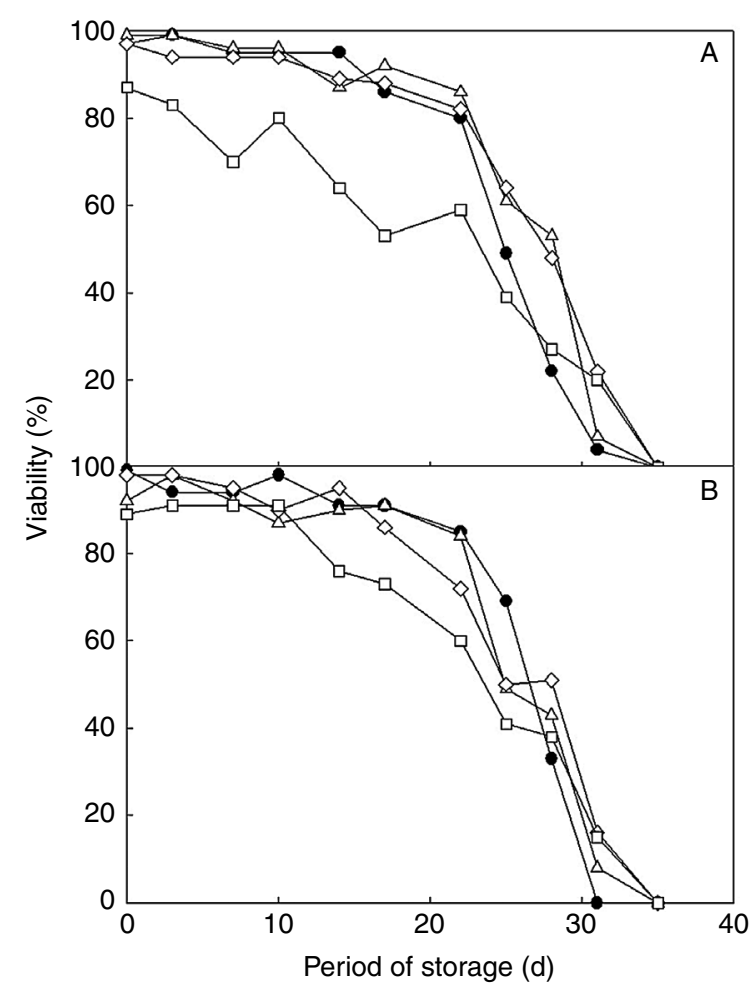

Figure 3. Seed survival curves (viability, estimated by ability to germinate, plotted against period of experimental hermetic storage at $40^{\circ} \mathrm{C}$ with $14.2-14.9 \%$ moisture content) for the japonica rice cv. Taipei 309 for seeds harvested 38 DAA (A) or 52 DAA (B) from plants grown in controlled environments of $28 / 20^{\circ} \mathrm{C}(\bullet)$ throughout, or at $28 / 20^{\circ} \mathrm{C}$ until 19 DAA and then $30 / 22^{\circ} \mathrm{C}(\triangle), 32 / 24^{\circ} \mathrm{C}(\diamond)$ or $34 / 26^{\circ} \mathrm{C}(\square)$ thereafter. 


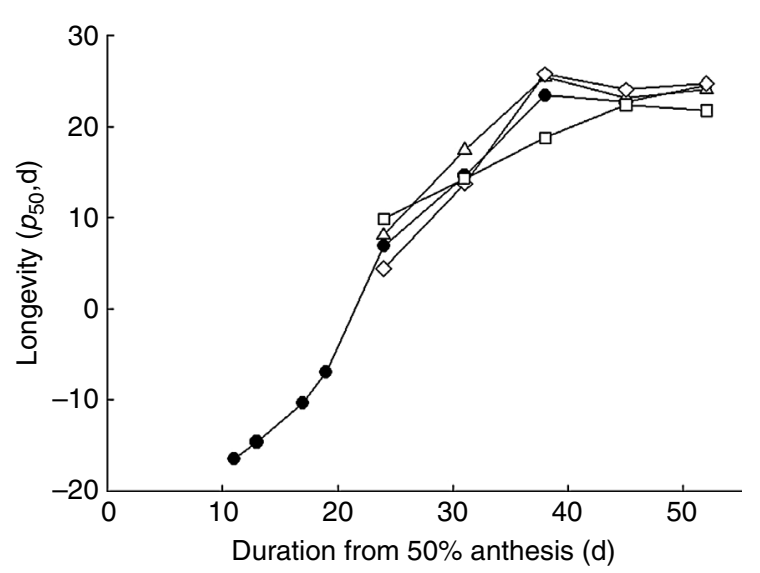

Figure 4. Changes in the longevity ( $p_{50}$, period of experimental hermetic storage at $40^{\circ} \mathrm{C}$ with $14.2-14.9 \%$ moisture content until viability reduced to $50 \%$; estimates provided by probit analysis) of seeds of japonica rice cv. Taipei 309 harvested serially during their development and maturation from plants grown in controlled environments of $28 / 20^{\circ} \mathrm{C}(\bullet)$ throughout, or at $28 / 20^{\circ} \mathrm{C}$ until $19 \mathrm{DAA}$ and then $30 / 22^{\circ} \mathrm{C}(\triangle), 32 / 24^{\circ} \mathrm{C}(\diamond)$ or $34 / 26^{\circ} \mathrm{C}(\square)$ thereafter. Seed filling ended close to 30 DAA (Fig. 1). The standard errors of the estimates of $p_{50}$ between 24 and 52 DAA were smaller than the symbols shown, varying only from 0.33 $\left(24 \mathrm{DAA}, 28 / 20^{\circ} \mathrm{C}\right)$ to $0.72 \mathrm{~d}\left(24 \mathrm{DAA}, 32 / 24^{\circ} \mathrm{C}\right)$. Estimates of $p_{50}$ for 11-19 DAA (note the negative values) are based on limited data since few dried seeds were viable (e.g. see Fig. 2B) and represent back extrapolation using the common value of $\sigma(9.5 \mathrm{~d})$ from 24 seed lots (i.e. all treatment combinations).

and so estimates of $K_{i}$ and $\sigma$ (equation 1), varied substantially amongst seed lots $(P<0.005)$. Thus $p_{50}$ (storage period in days to reduce viability to $50 \%$, the product of $K_{\mathrm{i}}$ and $\sigma$ ) was estimated separately for each lot in order to determine changes in air-dry seed storage potential during seed development and maturation, and to compare the four temperature regimes.

At $28 / 20^{\circ} \mathrm{C}$, seed longevity increased consistently and progressively throughout seed development and maturation until 38 DAA (when moisture content had first declined naturally to below 20\%) and then remained constant over the remainder of the investigation (Fig. 4). The three warmer temperature regimes provided a similar trend and also similar estimates of $p_{50}$ at any one date during seed development and maturation, except at 38 DAA when the warmest regime $\left(34 / 26^{\circ} \mathrm{C}\right)$ provided a shorter viability period than the cooler regimes (Fig. 4).

\section{Discussion}

Seed filling continued for longer than previously (Ellis et al., 1993; Ellis and Hong, 1994). Then, high ambient temperatures had resulted in the nominal $28 / 20^{\circ} \mathrm{C}$ being exceeded on occasion. In contrast, here it was difficult to warm to $28^{\circ} \mathrm{C}$ in the glasshouse after anthesis, even with supplemental heating. Hence, plants may have been disrupted during seed filling by this, the transfer to growth cabinets being implemented earlier than planned, and the lower light levels in the cabinets. The longer duration of seed filling also resulted in the different temperature regimes being imposed well before seed filling ended (seeds only $53 \%$ filled). Despite these differences amongst the studies (including light levels in growth cabinets being lower than ambient), mature seed dry weights were almost identical $[18.9 \mathrm{mg}$ compared with $17.5-17.6 \mathrm{mg}$ (Ellis et al., 1993) and $19.0-20.3 \mathrm{mg}$ (Ellis and Hong, 1994)], with no effect of temperature regime on mature seed dry weight within any of the three investigations.

The detection, magnitude and sign of any effects of temperature on seed quality development depend on the temperature(s) imposed, duration, species and cultivar. In wheat (Triticum aestivum L.), for example, there was good evidence of a positive effect of increase in temperature on the rate of improvement in potential seed longevity during seed development and maturation, but that study was at comparatively cool temperatures (Sanhewe et al., 1996). At slightly warmer temperatures in Phaseolus vulgaris L., on the other hand, increase in seed production temperature resulted in poorer subsequent seed longevity (Sanhewe and Ellis, 1996).

Seed quality, i.e. both desiccation tolerance and subsequent seed storage survival period, in this japonica rice increased considerably after mass maturity in all temperature regimes. The $2-6^{\circ} \mathrm{C}$ increase in mean temperature above $24^{\circ} \mathrm{C}$ was not imposed until late seed filling - and not until after the development of ability to germinate (Fig. 2A). The temperature treatments had no effect on the subsequent development of desiccation tolerance (Fig. 2). Neither did temperature affect the improvement in seed storage potential $\left(p_{50}\right)$ save perhaps for the warmest regime at $38-52$ DAA (Fig. 4). However, that regime $\left(34 / 26^{\circ} \mathrm{C}\right)$ did reduce the survival period of the shortest-lived seeds in each population, i.e. the first $60-80 \%$ to die (Fig. 3). This fraction of each population coincides approximately with that fraction (c. $80 \%$ ) which had not achieved desiccation tolerance by the time when the different temperatures were imposed (Fig. 2). Hence, there is some evidence that seed quality in certain seeds (possibly the last to develop) was damaged by the warmest regime.

Comparison of seed quality development between $28 / 20^{\circ} \mathrm{C}$ and $32 / 24^{\circ} \mathrm{C}$ when provided to this japonica rice throughout crop and seed development showed an abrupt change from mass maturity onwards (Ellis et al., 1993; Ellis and Hong, 1994): results for storage 
potential were similar until that point in development, but then diverged greatly with little or no further improvement at $32 / 34^{\circ} \mathrm{C}$ and considerable further improvement at $28 / 20^{\circ} \mathrm{C}$ for the next 12 days or so. The consequence was a $55 \%$ reduction in storage potential by harvest maturity (Ellis et al., 1993). The current study indicates that delaying the imposition of temperatures warmer than $28 / 20^{\circ} \mathrm{C}$ (within the range investigated) until two-thirds through the seed-filling phase results in comparatively little $\left(34 / 26^{\circ} \mathrm{C}\right)$ or no $\left(30 / 22^{\circ} \mathrm{C}, 32 / 24^{\circ} \mathrm{C}\right)$ damage to the storage potential of the mature seed (Fig. 4).

Three further comparisons are apposite. First, seed storage potential improved substantially post-mass maturity at all temperatures (Fig. 4), but only in the cooler regime previously (Ellis et al., 1993). Second, potential longevity at the warmer and cooler temperatures plateaued from 22 and 32 DAA, respectively, previously (Ellis et al., 1993), but from 38 or 45 DAA in the three coolest and the warmest regimes, respectively, here (Fig. 4). Third, extreme desiccation tolerance diverged from mass maturity onwards with difference in temperature when imposed throughout seed development and maturation (Ellis and Hong, 1994), but not when provided only late in development and maturation (Fig. 2C). All of which tends to suggest that, while previously the consequences were not manifest until after mass maturity, providing warmer temperature throughout seed development and maturation was more damaging to subsequent seed quality in this japonica rice than when it was not imposed until seeds were already half filled.

The hypothesis that the damaging effect of high temperature to seed quality development is reduced the later during seed development and maturation it is imposed - together with one (not mutually exclusive) that duration of high temperature is also a factor - is worthy of further investigation in rice, and other species. There is evidence in other aspects of reproductive biology of greater sensitivity to temperature at specific developmental stages. In particular, pollination, and so seed set, are particularly sensitive to brief exposure to high temperature, e.g. in rice (Yoshida et al., 1981; Prasad et al., 2006; Jagadish et al., 2010), groundnut (Arachis hypogaea L.) (Craufurd et al., 2003) and wheat (Wheeler et al., 1996; Ferris et al., 1998).

Anthropogenic greenhouse gas emissions are now considered very likely to have caused most of the global warming observed in the second half of the 20th century and may result in further warming of $1.3-1.8^{\circ} \mathrm{C}$ by around the middle of this century, with heat waves very likely to become more frequent, intense and longer (Solomon et al., 2007). The regimes of $28 / 20^{\circ} \mathrm{C}$ and $32 / 24^{\circ} \mathrm{C}$ represent major rice production areas and seasons in Japan and the Philippines, respectively (Ellis et al., 1993). Accordingly, the results to date imply that such an increase in mean temperature during seed development rather than during seed maturation in the former may hinder future production of quality seed (and so affect subsequent crop production) in japonica rices. Moreover, the absence of any impact on mean seed weight (at constant plant densities) suggests no effect on yield and thus that seed quality might be a more sensitive indicator than yield in order to monitor climate change impacts on crops in real time. More generally, seed quality in other rices in other regions might also be affected by climate change, as might other crops. Attempts to quantify the full impacts of climate change (and post-anthesis stress in particular) on crop production, therefore, may need to include the consequences for crop seed supply - quantity and quality - for subsequent seasons as well as the direct (within-season) impacts on crop production. Such considerations are likely to be particularly pertinent in regions where crop production is already marginal due to high temperature. If such impacts are to be understood and modelled, then it will be necessary to determine the extent to which the sensitivity of seed quality development to temperature might vary, depending upon precisely when during seed development and maturation high (or indeed cool) temperature episodes occur.

\section{Acknowledgements}

I thank Caroline Hadley and Laurence Hansen for their considerable, excellent technical support, Dr Fiona Hay (IRRI) for comments on a draft, and IRRI for donating the seed.

\section{References}

Craufurd, P.Q., Prasad, P.V.V., Kakani, V.G., Wheeler, T.R. and Nigam, S.N. (2003) Heat tolerance in groundnut. Field Crops Research 80, 63-77.

Demir, I. and Ellis, R.H. (1992a) Changes in seed quality during seed development and maturation in tomato. Seed Science Research 2, 81-87.

Demir, I. and Ellis, R.H. (1992b) Development of pepper (Capsicum annuum L.) seed quality. Annals of Applied Biology 121, 385-399.

Demir, I. and Ellis, R.H. (1993) Changes in potential seed longevity and seedling growth during seed development and maturation in marrow. Seed Science Research 3, 247-257.

Ellis, R.H. and Hong, T.D. (1994) Desiccation tolerance and potential longevity of developing seeds of rice (Oryza sativa L.). Annals of Botany 73, 501-506.

Ellis, R.H. and Pieta-Filho, C. (1992) The development of seed quality in spring and winter cultivars of barley and wheat. Seed Science Research 2, 9-15. 
Ellis, R.H. and Roberts, E.H. (1980) Improved equations for the prediction of seed longevity. Annals of Botany 45, 13-30.

Ellis, R.H., Hong, T.D. and Roberts, E.H. (1983) Safe procedures for the removal of rice seed dormancy. Seed Science and Technology 11, 77-112.

Ellis, R.H., Hong, T.D. and Jackson, M.T. (1993) Seed production environment, time of harvest, and the potential longevity of seeds of three cultivars of rice (Oryza sativa L.). Annals of Botany 72, 583-590.

Ferris, R., Ellis, R.H., Wheeler, T.R. and Hadley, P. (1998) Effect of high temperature stress at anthesis on grain yield and biomass of field-grown crops of wheat. Annals of Botany 82, 631-639.

Hay, F.R. and Probert, R.J. (1995) The effect of different drying conditions and maturity on desiccation tolerance and seed longevity in Digitalis purpurea L. Annals of Botany 76, 639-647.

International Seed Testing Association (2005) International Rules for Seed Testing. Edition 2005. Switzerland, The International Seed Testing Association.

Jagadish, S.V.K., Muthurajan, R., Oane, R., Wheeler, T.R., Heuer, S., Bennett, J. and Craufurd, P.Q. (2010) Physiological and proteomic approaches to address heat tolerance during anthesis in rice (Oryza sativa L.). Journal of Experimental Botany 61, 143-156.

Pieta Filho, C. and Ellis, R.H. (1991) The development of seed quality in spring barley in four environments. I. Germination and longevity. Seed Science Research 1, $163-177$.

Prasad, P.V.V., Boote, K.J., Allen, L.H., Sheehy, J.E. and Thomas, J.M.G. (2006) Species, ecotype and cultivar differences in spikelet fertility and harvest index of rice in response to high temperature stress. Field Crops Research 95, 398-411.

Rao, N.K. and Jackson, M.T. (1996) Seed production environment and storage longevity of japonica rices (Oryza sativa L). Seed Science Research 6, 17-21.

Rao, N.K. and Jackson, M.T. (1997) Effect of sowing date and harvest time on longevity of rice seeds. Seed Science Research 7, 13-20.

Rao, N.K., Appa Rao, S., Mengesha, M.H. and Ellis, R.H. (1991) Longevity of pearl millet (Pennisetum glaucum) seeds harvested at different stages of maturity. Annals of Applied Biology 119, 97-103.

Sanhewe, A.J. and Ellis, R.H. (1996) Seed development and maturation in Phaseolus vulgaris. II. Post-harvest longevity in air-dry storage. Journal of Experimental Botany 47, 959-965.

Sanhewe, A.J., Ellis, R.H., Hong, T.D., Wheeler, T.R., Batts, G.R., Hadley, P. and Morison, J.I.L. (1996) The effect of temperature and $\mathrm{CO}_{2}$ on seed quality development in wheat (Triticum aestivum L.). Journal of Experimental Botany 47, 631-637.

Solomon, S., Qin, D., Manning, M., Chen, Z., Marquis, M., Averyt, K.B., Tignor, M. and Miller, H.L. (Eds) (2007) Climate Change 2007: The Physical Science Basis. Contribution of Working Group I to the Fourth Assessment Report of the Intergovernmental Panel on Climate Change. Cambridge, UK, Cambridge University Press.

Wheeler, T.R., Batts, G.R., Ellis, R.H., Hadley, P. and Morison, J.I.L. (1996) Growth and yield of winter wheat (Triticum aestivum) crops in response to $\mathrm{CO}_{2}$ and temperature. Journal of Agricultural Science, Cambridge 127, 37-48.

Yoshida, S., Satake, T. and Mackill, D. (1981) High temperature stress in rice. IRRI Research Paper Series 67, 1-15. 